\title{
75 years of RILEM: Materials \& Structures papers that have shaped the research landscape
}

\author{
Nicolas Roussel
}

Accepted: 6 December 2021/Published online: 12 January 2022

(C) RILEM 2021

\section{RILEM, RILEM members and Materials and Structures}

The International Union of Laboratories and Experts in Construction Materials, Systems and Structures (RILEM, from the name in French) was founded in June 1947, with the aim to promote scientific cooperation in the area of construction materials and structures. Since the creation of RILEM, this mission has been achieved through collaboration of leading experts in construction practice and science, including academics, researchers, testing laboratories and authorities for all around the world. Within the frame offered by the association, cooperation at an international scale steadily grew, promoting, in parallel to technical achievements, a universal and general access to advanced knowledge.

Materials and Structures, the flagship publication of RILEM, was launched in 1968. It has since provided a unique international and interdisciplinary forum for new research findings in the field of construction materials and structures. But, more than anything, Materials and Structures has been through all these years the mirror of the RILEM activities by publishing comprehensive reports or technical recommendations prepared by RILEM's technical committees along with the prestigious and awaited Robert

N. Roussel ( $\square)$

RILEM, Paris, France

e-mail: nicolas.roussel@ifsttar.fr
L'Hermite medalists' annual invited paper. Last but not least, most of the association's senior and famous members have often chosen during their careers to publish their greatest advances in this journal.

\section{Today's world situation and collective knowledge as a link between people}

All the publications gathered in RILEM books and, more than anything, in Materials and Structures are the collective knowledge we share. They can be accessed by any RILEM member with an internet connection. In times such as the ones we are living now, they are the link between all members of RILEM and, more generally, between all professionals in the field of construction. After almost two years of computer screens, online meetings and lectures given from our kitchens, when human bonds start to weaken, we still share this legacy of our technical knowledge, stored on paper or in the cloud, and it still makes us feel like we belong to a community. They are the robust shoulders upon which we can keep on promoting sustainable and safe construction for society, despite the pandemic.

\section{RILEM collective construction of knowledge}

The RILEM way of constructing knowledge is very specific to the association. In general, scientists generate knowledge through observations, 
experiments, and simulations. However, as they do so at an individual or small research group level, there is always a risk of measurement artefacts, wrong interpretation, or over-interpretation of data. This may, in turn, lead to failures of so-called "scientific objectivity". Most scientific communities generally, and maybe naively according to some authors [1], consider themselves as self-correcting by nature, through replication and debates. Nevertheless, this self-correcting process takes time. In RILEM history of knowledge construction, replication and debates are embedded in the roots of the association structure and modus operandi. Most technical committees organize interlaboratory testing right from their start, and the numerous RILEM conferences are the ideal frame within which theories get confronted.

Within such a collective frame, choosing a few papers to celebrate the $75^{\text {th }}$ birthday of the association has proven to be extremely delicate and may, moreover, sound contradictory to the collaborative and collective knowledge construction pattern of RILEM.

\section{The community behind the selected papers}

The papers gathered in this special issue are considered as the ones that have shaped today's research landscape. Within the collective knowledge construction process discussed above, they are the ones that did survive, in a Darwinist sense, all trials of replication and all confrontations.

Behind these papers, there were communities or technical committees debating. There were other authors and other papers making different statements and stimulating discussions. There were anonymous reviewers improving these masterpieces through their suggested revisions. These papers were followed by other papers written by other authors that did confirm the robustness of the proposed test or the accuracy of the proposed model. These papers were naturally thereafter very much cited by other members of our community as they were a solid point of anchorage for further developments. More than anything, these papers all have in common to correspond to a point in time where one or a few individuals wrote a statement or decided on a method that everybody quickly agreed upon back then.

\section{A final word}

The papers gathered in this special issue cover a large range of topics typical of RILEM fields of expertise. They range from bitumen to high performance concretes, from fresh materials ready to be processed to aged ones ready to be repaired. They present test methods, underlying physics and chemistry, numerical prediction tools or conceptual frames. I personally took a lot of pleasure in discovering or rediscovering these papers and I hope you will enjoy these as much as I did.

Nicolas Roussel, RILEM president.

\section{Reference}

1. Ioannidis JPA (2012) Why science is not necessarily selfcorrecting. Perspect Psychol Sci 7(6):645-654. https://doi. org/10.1177/1745691612464056

Publisher's Note Springer Nature remains neutral with regard to jurisdictional claims in published maps and institutional affiliations. 